RAE-IC, Revista de la Asociación Española de Investigación de la Comunicación

vol. 8, núm. 16 (2021), 425-427

ISSN 2341-2690

DOI: https://doi.org/10.24137/raeic.8.16.19

(c) (i) (2)

\title{
Diccionario de Teorías Narrativas 2
}

\section{Diccionario de Teorías Narrativas 2}

\author{
de Souza, Sergio \\ Universidade Federal de Rio de Janeiro (UFRJ) \\ sbrasil@uol.com.br
}

Forma de citar este artículo:

de Souza, S. (2021). Diccionario de Teorías Narrativas 2. RAE-IC, Revista de la Asociación Española de Investigación de la Comunicación, 8(16), 425-427.

https://doi.org/10.24137/raeic.8.16.19 


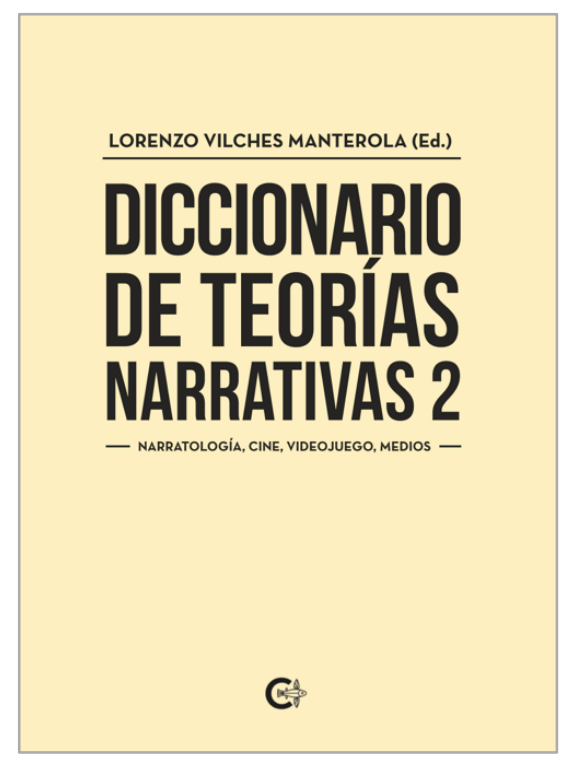

Título: Diccionario de Teorías Narrativas 2

Editor: Vilches Manterola, Lorenzo

Editorial: Caligrama. Penguin Random House

Páginas: 883

ISBN: 9788418152726

El lenguaje siempre ha sido mágico y la revelación crítica de sus componentes expresó un fuerte interés intelectual en sus juegos compositivos. Walter Benjamin, por ejemplo, aplicó al lenguaje un encuentro entre el sujeto hablante y su propia identidad. Bakhtin acusó al lenguaje de esconder una dinámica polifónica en la que la palabra no indicaba más que una realidad que estallaba en concepciones del mundo. Otros autores, para no agotarnos con indicaciones, han tratado el lenguaje en sus más complejas producciones, intentando establecer ciertas similitudes y formas de decodificación. El campo de la Narratología se expande y, generalmente influenciado por pautas estructuralistas, señala autores que se articulan cada vez más en el desciframiento del misterio de las narrativas. Pensadores como Todorov, Eco, Propp, Lévi-Strauss, Greimas, Genette, Lotman, Prince, Foucault, Barthes y muchos otros lideraron reflexiones que hicieron posible la liberación de la narratología. Anteriormente un conocimiento restringido, aunque relevante, de los estudios que englobaba la crítica literaria, las teorías narrativas ahora integran obligatoriamente el vasto espacio de las ciencias sociales, en particular, de las articulaciones producidas por la teoría de la comunicación. Esta apasionante nueva articulación del saber queda plenamente confirmada por la publicación del segundo volumen del excelente Diccionario de Teorías Narrativas 2, de Lorenzo Vilches Manterola, catedrático 
emérito de la Universitat Autònoma de Barcelona y una de las principales autoridades europeas en la materia.

Acceder a la multitud de materias que ofrece este Diccionario no es una tarea difícil para el lector, como cualquier buen diccionario. Con articulaciones idénticas al primer volumen y nuevos acercamientos con felices hallazgos metodológicos, el profesor Dr. Vilches nos permite una conexión detallada entre los temas, los autores y las investigaciones aplicadas a los campos de la literatura narrativa, del cine, la emoción de los juegos y los desafíos visuales del mundo digital, y también las contradicciones y superaciones obtenidas por las diversas teorías narrativas. Su dinámica interna y orgánica hacen del Diccionario un excelente sistema de conexiones y articulaciones estructurantes, permitiendo al lector brindar señales que lo lleven a comprender y descifrar dudas e inexactitudes. Una oferta para cualquier tipo de lector o especialista, reitero, en el vasto campo de las ciencias sociales, incluida la filosofía. Para el buen investigador, una herramienta bibliotecaria indispensable y para los "detectives" interesados en descubrimientos útiles, un libro instigador para resolver lo que ocurre en el campo de las ciencias narrativas. No poseerlo, una pérdida intelectual. 